\title{
Tolerance to oats in dermatitis herpetiformis
}

\author{
T Reunala, P Collin, K Holm, P Pikkarainen, A Miettinen, N Vuolteenaho, M Mäki
}

\section{Departments of Dermatology, University and University Hospitals of Tampere and Helsinki, Finland \\ T Reunala}

Departments of Medicine, Paediatrics and Clinical

Microbiology, Tampere University Hospital and University of

Tampere

P Collin

K Holm

P Pikkarainen

A Miettinen

Institute of Medical Technology and Medical School, University of Tampere N Vuolteenaho M Mäki

Correspondence to: Dr T Reunala, Department of Dermatology, Helsinki University Hospital, Meilahdentie 2, FIN-00250 Helsinki, Finland.

Accepted for publication 8 April 1998

\begin{abstract}
Objectives-Recent studies on coeliac disease have shown that oats can be included in a gluten-free diet without adverse effects on the small bowel. The presence of a rash is also a sensitive indicator of gluten ingestion in dermatitis herpetiformis, and this was used to study whether patients with this disease could also tolerate oats.

Patients/Methods-Eleven patients with dermatitis herpetiformis in remission on a gluten-free diet were challenged daily with $50 \mathrm{~g}$ oats for six months. Clinical symptoms were recorded, serum samples taken, and skin and small bowel biopsies performed before and after the oat challenge. A control group comprised of 11 patients with dermatitis herpetiformis on a conventional gluten-free diet was also studied.

Results-Eight patients challenged with oats remained asymptomatic, two developed a transient rash, and one withdrew because of the appearance of a more persistent but mild rash. Three of the 11 controls also developed a transient rash. IgA endomysial antibodies remained negative in all patients. The small bowel villous architecture, the densities of intraepithelial CD3 and $\alpha / \beta$ and $\gamma / \delta \mathrm{T}$ cell receptor positive lymphocytes and crypt epithelial cell DR expression remained unaltered during the oat challenge.

Conclusions-The results confirm the absence of oat toxicity on the gluten sensitive small bowel mucosa and suggest that the rash in patients with dermatitis herpetiformis is not activated by eating oats.

(Gut 1998;43:490-493)
\end{abstract}

Keywords: dermatitis herpetiformis; coeliac disease; gluten-free diet; oats

Dermatitis herpetiformis is a specific cutaneous manifestation of coeliac disease with a symmetrical pruritic rash and pathognomonic IgA deposits in the skin. ${ }^{1}$ Gastrointestinal symptoms are infrequent. However, about $80 \%$ of patients with dermatitis herpetiformis have villous atrophy and the rest show inflammatory changes in the small bowel mucosa. ${ }^{2}$ The enteropathy and the rash respond to a glutenfree diet, ${ }^{3}{ }^{4}$ but there is a relapse when the diet is withdrawn, ${ }^{5}$ and therefore patients with dermatitis herpetiformis, like those with coeliac disease, must adhere to a gluten-free diet for life.
Wheat, barley, rye, and oats are excluded from the conventional gluten-free diet. Recent studies suggest a lack of oat toxicity in coeliac disease - that is, patients showed no clinical or histological relapse when challenged with oats for three or six months. ${ }^{6}$ As the development of a rash is a sensitive indicator of gluten ingestion in dermatitis herpetiformis, we used this to study whether patients in remission could also tolerate oats. The immunogenic potential of oats was examined by observing IgA deposits in the skin, endomysial and gliadin antibodies in the serum, and intraepithelial $\mathrm{T}$ cell densities and crypt epithelial cell HLA-DR expression in the small bowel.

\section{Patients and methods}

Twelve patients with dermatitis herpetiformis on a conventional gluten-free diet were recruited for the oat challenge study. At diagnosis, all patients had a typical rash and IgA deposits, five had subtotal and four partial villous atrophy, and three showed slight changes in the small bowel. At inclusion in the study, the patients had been on a gluten-free diet for 5.5 years (mean; range $0.5-19$ ), had been free of rash for 14 months (mean; range 2-48), and none of them used dapsone. The patients were assessed clinically and dietetically one to two months before, at the beginning, and one, three, and six months after the oat challenge. One patient developed a rash before the oat challenge and was excluded. Eleven patients with dermatitis herpetiformis (five men, six women; mean age 51, range 30-67 years) on a conventional gluten-free diet volunteered to act as controls to study possible exacerbation of the rash. At diagnosis, three patients had subtotal and six partial villous atrophy, and two showed slight changes in the small bowel. At inclusion, the control patients had been on a gluten-free diet for a mean (range) of 2.5 (1-4) years, rash-free for 12 (4-24) months, and none of them had used dapsone.

The study was approved by the ethics committee of Tampere University Hospital, and all patients gave informed consent.

The duration of the oat challenge was six months. The patients were asked to consume $50 \mathrm{~g}$ oats daily as porridge or home baked bread while otherwise maintaining a conventional gluten-free diet. The oat cereal (Melia Ltd, Raisio, Finland) given to the patients was free of gluten contamination as studied by enzyme linked immunosorbent assay (ELISA; Ridascreen Gluten Kit, Biopharm, Darmstadt, Germany) and polymerase chain reaction. ${ }^{8}$ The amounts of oats and gluten consumed 
Table 1 Cutaneous findings during the oat challenge in 11 patients with dermatitis herpetiformis on a gluten-free diet

\begin{tabular}{|c|c|c|c|c|c|c|c|c|}
\hline \multirow[b]{2}{*}{ Patient } & \multirow{2}{*}{$\begin{array}{l}\text { Sex/age } \\
\text { (y) }\end{array}$} & \multirow{2}{*}{$\begin{array}{l}\text { Initial jejunal } \\
\text { biopsy/duration of diet }(y)\end{array}$} & \multicolumn{4}{|l|}{ Rash } & \multicolumn{2}{|c|}{ IgA fluorescence } \\
\hline & & & At baseline & 1 month & 3 months & 6 months & At baseline & 6 months \\
\hline 1 & $M / 36$ & $\mathrm{SVA} / 2$ & - & - & - & - & - & - \\
\hline 2 & $\mathrm{M} / 56$ & $\mathrm{~N} / 5$ & - & - & - & - & - & - \\
\hline 3 & $\mathrm{~F} / 38$ & $\mathrm{SVA} / 8$ & - & - & - & - & - & - \\
\hline 4 & $\mathrm{~F} / 61$ & $\mathrm{~N} / 0.5$ & - & - & - & - & - & + \\
\hline 5 & $\mathrm{~F} / 60$ & $\mathrm{SVA} / 3$ & - & - & - & - & + & + \\
\hline 6 & $\mathrm{~F} / 36$ & SVA $/ 19$ & - & - & - & - & ++ & + \\
\hline 7 & $M / 56$ & PVA/15 & - & - & - & - & ++ & ++ \\
\hline 8 & $\mathrm{~F} / 43$ & $\mathrm{~N} / 4$ & - & - & + & - & + & + \\
\hline 9 & $\mathrm{M} / 53$ & PVA $/ 3$ & - & + & + & - & ND & ND \\
\hline 10 & $\mathrm{~F} / 51$ & $\mathrm{PVA} / 3$ & - & + & + & ND & + & $+t$ \\
\hline 11 & $\mathrm{M} / 36$ & $\mathrm{~N} / 3$ & - & - & - & ND & + & ND \\
\hline
\end{tabular}

ॠWithdrawal or dropout.

†Performed at three months.

SVA, subtotal villous atrophy; PVA, partial villous atrophy; $\mathrm{N}$, slight changes or normal mucosa; $\mathrm{ND}$, not done.

from wheat-starch flours (allowed to contain up to $0.3 \mathrm{~g}$ protein - that is, $50 \mathrm{mg}$ gluten-per 100 g flour; Codex Alimentarius 118-1981) were assessed from food diaries kept at home. The control patients remained on their gluten-free diet and were assessed clinically and dietetically at zero, one and three months.

The presence or absence of a rash was recorded from the diaries and checked on every visit. A biopsy specimen was taken from the forearm before and at the end of the oat challenge, and IgA fluorescence was graded as intense $(++)$, weak $(+)$, or negative $(-)$. Serum samples taken at zero, three, and six months were screened at 1:5 and 1:50 dilutions for IgA class endomysial antibodies using human umbilical cord as substrate. ${ }^{9}$ IgA class gliadin antibodies were measured by ELISA, and values above $0.20 \mathrm{EU} / \mathrm{ml}$ were regarded as positive. ${ }^{9}$

Upper gastrointestinal endoscopy was performed before and at the end of the oat challenge. Specimens taken from the distal part of the duodenum were processed for measurement of villous height:crypt depth ratio and immunohistochemical examination. ${ }^{10}{ }^{11}$ Intraepithelial CD3 and $\alpha / \beta$ T cell receptor (TCR) positive and $\gamma / \delta$ TCR positive lymphocytes were stained with monoclonal antisera (Leu-4, diluted 1:5, from Becton Dickinson, San Jose, California, USA; $\beta F 1$, diluted 1:80, from $\mathrm{T}$ Cell Diagnostics, Woburn, Massachusetts, USA; TCR $\gamma$, diluted 1:40, from $\mathrm{T}$ Cell Diagnostics) and Vectastain Elite ABC kit (Vector Laboratories, Burlingame, California, USA), and the densities were expressed as cells/mm of epithelium. HLA-DR expression in the crypt epithelial cells was also studied

Table 2 Small bowel findings before and after six months'oat challenge in 10 patients with dermatitis herpetiformis (DH) on a gluten-free diet and in 28 dyspeptic control patients without gluten intolerance

\begin{tabular}{llcl}
\hline & \multicolumn{2}{l}{ Patients with DH on oats challange } & \\
\cline { 2 - 3 } & \multicolumn{1}{l}{ Before } & Aftert & \multirow{2}{*}{ Controls } \\
\hline Villous height:crypt depth ratio & $3.0(1.0)$ & $2.8(0.8)$ & $3.8(1.3)$ \\
Intraepithelial lymphocytes (cells/mm epithelium) & & \\
CD3 positive & $37.6(16.4)$ & $34.8(17.5)$ & $25.6(16.5)$ \\
$\alpha / \beta T C R$ positive & $14.8(5.0)$ & $15.1(7.7)$ & $15.7(11.8)$ \\
$\gamma / \delta$ TCR positive & $9.1(4.8)^{\star}$ & $6.0(5.1)$ & $1.5(1.6)$ \\
DR expression in crypts & $2 / 10$ & $2 / 10$ & $3 / 28$ \\
\hline
\end{tabular}

Results are expressed as mean (SD)

$\star$ Significant $(\mathrm{p}<0.001)$ difference compared with controls.

tIncludes data from one patient after three months of oat challenge.
(HLA-DR, diluted 1:500; Becton Dickinson). ${ }^{11}$ For comparison, small bowel specimens were taken from 28 patients (15 men, 13 women; mean age 52 years, range 25-81) suffering from dyspepsia.

Paired $t$ test was used to compare villous height:crypt depth ratios and intraepithelial lymphocyte densities before and after the oat challenge. Two tailed $t$ test was used to compare the lymphocyte densities between the patients with dermatitis herpetiformis and controls.

\section{Results}

Eight of the 11 patients with dermatitis herpetiformis remained asymptomatic during the oat challenge but one dropped out before the final visit (table 1). One patient developed a mild rash on her scalp after six weeks on the oat challenge and therefore withdrew from the study at the three month visit. In addition, two patients had a mild temporary rash lasting three or four weeks (table 1). IgA fluorescence in the skin remained unchanged in six, decreased in one and became positive in one patient (table 1). None of the patients developed IgA endomysial antibodies. One asymptomatic patient had IgA gliadin antibodies (1.06, 0.81, and $0.69 \mathrm{EU} / \mathrm{ml} \mathrm{respec}-$ tively) throughout the study and one in the three month serum sample $(0.36 \mathrm{EU} / \mathrm{ml})$. Three of the 11 control patients developed a rash during the three month follow up. One patient had a moderate rash on the elbows and knees for two months, and the other two had a mild temporary rash at the one month visit. At baseline, two control patients had intense $(+++)$, four weak $(+)$, and five negative $(-)$ IgA fluorescence of the skin. All three controls who developed rashes had IgA deposits in the skin but none of them had IgA endomysial or gliadin antibodies.

Before the oat challenge, the patients with dermatitis herpetiformis had somewhat lower villous height:crypt depth ratios $(p=0.082)$ and significantly $(\mathrm{p}<0.001)$ higher densities of intraepithelial $\gamma / \delta$ TCR positive lymphocytes than the control patients (table 2). During the oat challenge, the patients consumed a mean (range) of 53.2 (30-66) g oats daily, and the mean gluten intake from wheat-starch flours was $40(0-150) \mathrm{mg} /$ day. The oat challenge did 
not cause any significant changes in the mean villous height:crypt depth ratio nor in the densities of intraepithelial CD3 and $\alpha / \beta$ or $\gamma / \delta$ TCR positive lymphocytes (table 2). The patient who withdrew at the three month visit because of the development of a rash showed a slight decrease in the villous height:crypt depth ratio (3.3 and 2.8) but no increase in the densities of CD3 (34.1 and 30.7 cells $/ \mathrm{mm}$ ), $\alpha / \beta$ TCR positive $(10.1$ and 11.1 cells $/ \mathrm{mm}$ ) and $\gamma / \delta$ TCR positive $(7.5$ and 8.3 cells $/ \mathrm{mm}$ ) lymphocytes. DR expression in the crypt epithelial cells was positive in two patients at the beginning but not at the end of the oat challenge (table 2). Another two patients showed positive staining at the end but not at the beginning of the oat challenge.

\section{Discussion}

The six month oat challenge showed that most patients with dermatitis herpetiformis on a conventional gluten-free diet could take $50 \mathrm{~g}$ oats daily without reappearance of the rash. By comparison, in the study of Leonard et $a l^{5}$ a challenge with $10 \mathrm{~g}$ wheat gluten and simultaneous normal diet resulted in the reappearance of the rash after a mean of 12 weeks in 11 of the 12 patients with dermatitis herpetiformis. Moreover, IgA deposits returned to the skin in all of their three patients in whom IgA was absent before the gluten challenge. In the present study, IgA was observed in the skin in only one of the four patients with initially negative biopsy results, but this patient did not develop a rash. The reason why the three patients with dermatitis herpetiformis, including the patient who withdrew from the study, had a mild rash during the oat challenge without any signs of immune activation in the skin, serum, or gut remains unclear. Temporary rash flare ups are not uncommon during treatment with a conventional gluten-free diet, ${ }^{4}$ as was also seen in three of the 11 control patients in this study. The temporary flare ups might, therefore, be due to occasional dietary lapses. Interestingly, IgA was still present in the skin in all six patients and controls who developed a rash during the study. By contrast IgA deposits were seen in only half of those patients and controls who did not develop a rash. This suggests that patients with IgA deposits are more likely to develop a rash when on a gluten-free diet than those in whom IgA has disappeared from the skin.

The major finding of the present oat challenge study is that most of the patients with dermatitis herpetiformis developed no cutaneous symptoms when adhering to a conventional gluten-free diet and taking $50 \mathrm{~g}$ oats daily for six months. Higher daily amounts or intake for longer than six months may be deleterious to the patients. Interestingly, several of our patients found it difficult to continue to eat as much as $50 \mathrm{~g}$ of oats a day during the last few weeks of the study. However, eight of our nine patients with dermatitis herpetiformis have now consumed oats for up to 12 months and they have all remained symptom-free. In addition, a five year follow up of patients with coeliac disease on the oat-containing glutenfree $\operatorname{diet}^{12}$ also supports the assertion that these patients can tolerate moderate amounts of oats in the diet for long periods of time.

In agreement with previous studies on coeliac disease,${ }^{67}$ the present challenge with the same daily amount of oats did not cause any gastrointestinal symptoms or morphological changes in the small bowel in any of the patients with dermatitis herpetiformis. In addition, we examined for the first time during the oat challenge the densities of intraepithelial CD 3 and $\alpha / \beta$ and $\gamma / \delta$ TCR positive lymphocytes, and HLA DR expression in the crypt epithelial cells. Small bowel intraepithelial lymphocytes, and CD 3 and $\alpha / \beta$ TCR positive $\mathrm{T}$ cells in particular, are as sensitive indicators of gluten ingestion in dermatitis herpetiformis as they are in coeliac disease. ${ }^{2}{ }^{13}$ Moreover, IgA class endomysial and gliadin antibodies are also serological markers of small bowel damage in dermatitis herpetiformis. ${ }^{9}$ All of these sensitive indicators of gluten ingestion remained unaltered during the present oat challenge. The density of intraepithelial $\gamma / \delta$ TCR positive lymphocytes was similarly increased before and after the oat challenge, a finding that is in agreement with previous studies in patients with dermatitis herpetiformis on a conventional gluten-free diet. ${ }^{2}$ The lack of immunological effects of oats may be due to differences in the molecular structures of cereal prolamins-that is, between avenin in the oats and gliadin in the wheat-and also to a much lower concentration of avenin in the oats compared with gliadin in the wheat. ${ }^{14}$

The present six month challenge study with moderate amounts of oats in patients with dermatitis herpetiformis did not disclose any tendency for reappearance of the rash or signs of immune activation known to occur in the skin, serum, or gut mucosa after exposure to wheat gluten. We conclude therefore that oats are a new cereal alternative for patients with dermatitis herpetiformis on a strict gluten-free diet and whose rash is in remission. The inclusion of oats in a gluten-free diet increases the variety of cereals that can be consumed, which may improve compliance, and also reduce the otherwise high cost of such treatment.

While we were revising this paper, a similar study was published. ${ }^{15}$ In agreement with our results, no adverse effects were seen in the skin or duodenal villous architecture in 10 patients with dermatitis herpetiformis challenged for three months with oats.

We are grateful to Dr Tuula Puolakka for help in patient care, Dr Philipp Hübner, Institute of Biochemistry, University of Bern, for performing gliadin measurements, and Ms Mervi Himanka for technical assistance with immunohistochemistry. The study was funded by the Finnish Coeliac Society (TR), the Medical Academy of Finland (MM), and the Research Fund of Tampere Academy of Finland (MM), and the Research Fund of Tampere
University Hospital (PC). This work was reported in part at the University Hospital (PC). This work was reported in part at the
Seventh International Symposium on Coeliac Disease, TamSeventh International Symposium on
pere, Finland, September 5-7, 1996.

1 Gawkrodger DJGA, Blackwell JN, Gilmour HM, et al. Dermatitis herpetiformis: diagnosis, diet and demography. Gut 1984;25:151-7. 
2 Savilahti E, Reunala T, Mäki M. Increase of lymphocytes bearing $\gamma / \delta \mathrm{T}$ cell receptor in the jejunum of patients with dermatitis herpetiformis. Gut 1992;33:206-1

3 Fry L, Seah PP, Riches DJ, et al. Clearance of skin lesions in dermatitis herpetiformis after gluten withdrawal. Lancet $1973 ; \mathbf{i}: 288-91$

4 Reunala T, Blomqvist K, Tarpila S, et al. Gluten-free diet in dermatitis herpetiformis. I. Clinical response in 81 patients. Br F Dermatol 1977;97:473-80.

5 Leonard J, Haffenden G, Tucker W, et al. Gluten challenge in dermatitis herpetiformis. $N$ Engl F Med 1982;308:816-19.

6 Janatuinen EK, Pikkarainen PH, Kemppainen TA, et al. A comparison of diets with and without oats in adult celiac disease. N Engl f Med 1995;333:1033-7.

7 Srinivasan U, Leonard N, Jones E, et al. Absence of oats toxicity in adult coeliac disease. BMf 1996;313:1300-1.

8 Köppel E, Stadler M, Lüthy J, et al. Oats and gliadin. In: Collin P, Mäki M, eds. Abstracts of the Seventh International Symposium on Coeliac Disease; 1996 Sept 5-7; Tampere, Finland. Tampere: Lege Antis, 1996.

9 Reunala T, Chorzelski T, Viander M, et al. IgA antiendomysial antibodies in dermatitis herpetiformis: correlation with jejunal morphology, gluten-free diet and antigliation with jejunal morphology, gluten-free diet and
din antibodies. Br f Dermatol 1987;117:185-91.
10 Holm K, Mäki M, Savilahti E, et al. Intraepithelial $\gamma / \delta$ T-cell-receptor lymphocytes and genetic susceptibility to T-cell-receptor lymphocytes and genetic
coeliac disease. Lancet 1992;339:1500-3.

11 Holm K, Savilahti E, Koskimies S, et al. Immunohistochemical changes in the jejunum of the first degree relatives of patients with coeliac disease and the coeliac disease marker DQ genes. HLA class II antigen expression, interleukin-2 receptor positive cells and dividing crypt cells. Gut 1994;23:55-60.

12 Janatuinen E, Kemppainen T, Kosma V-M, et al. Oats in coeliac diet; a 5-year follow-up study. In: Collin P, Mäki M, eds. Abstracts of the Seventh International Symposium on Coeliac Disease; 1996 Sept 5-7; Tampere, Finland. Tampere: Lege Antis, 1996.

13 Ferguson A, Blackwell JN, Barnetson RStC. Effect of additional dietary gluten on the small intestinal mucosa of volunteers and patients with dermatitis herpetiformis. Scand $\mathcal{F}$ Gastroenterol 1987;22:543-9.

14 Schmitz J. Lack of oats toxicity in coeliac disease. Toxic fraction makes up less of total protein than in other cereals [editorial]. BMf 1997;314:159-60.

15 Hardman CM, Garioch JJ, Leonard JN, et al. Absence of toxicity of oats in patients with dermatitis herpetiformis. $N$ Engl f Med 1997;337:1884-7. 